\title{
Variability of Climate-Induced Rice Yields in Northwest Bangladesh Using Multiple Statistical Modeling
}

\author{
Abu Reza Md. Towfiqul Islam \\ Prince of Songkla University \\ Irtifa Alam Nabila \\ Bangladesh University of Professionals \\ Md. Hasanuzzaman \\ Begum Rokeya University \\ Md. Bozlar Rahman \\ Begum Rokeya University \\ Ahmed Elbeltegi \\ Mansoura University \\ Javed Mallick \\ King Khalid University \\ Kuaanan Techato ( $\nabla$ uhugua@hotmail.com ) \\ Prince of Songkla University
}

\section{Research Article}

Keywords: Spatiotemporal variation, Climate Change, Rice Yield, Multiple linear modeling, Trend Analysis, Bangladesh

Posted Date: November 11th, 2021

DOl: https://doi.org/10.21203/rs.3.rs-892731/v1

License: (c) (i) This work is licensed under a Creative Commons Attribution 4.0 International License. Read Full License 


\section{Abstract}

Because of evident climatic variations and significant contribution to national food production, Bangladesh is a climate extreme hotspot region of examination for climatic consequences for rice (Oryza Sativa) crop production. This study intends to explore the variability of climatic variables (e.g., variations in mean temperature, rainfall, relative humidity, and sunshine duration) with rice yields (e.g., Aus, Aman, and Boro rice varieties) in northwest Bangladesh. The modified Mann-Kendall test, Theil-Sen slope estimator, and multiple linear regression (MLR) modeling were used to estimate the association among these factors. Heteroskedasticity and autocorrelation constant standard error (HAC) and feasible generalized least square (FGLS) technique were adopted to measure the climate-rice crop nexus using the regional level dataset for 1976-2015. Furthermore, the spatiotemporal variation of rice yield trends with climatic variables was mapped and assessed by the coefficient of variation. The results show that observed temperature and humidity trends were beneficial for Aus and Aman yields but not Boro yields. In contrast, observed rainfall and sunshine trends were negative for all three rice seasons. The outcomes of the MLR model explained $67 \%, 92 \%$, and $83 \%$ of the variability in Aus, Aman, and Boro rice yields in the study region. The model outcomes showed that humidity and rainfall have negatively affected Aus and Aman rice crops, while temperature and rainfall positively influence Boro rice yield. Regarding the climate change issues and safeguarding food safety at the regional level, the concerned authorities should provide substantial attention to improving heat and drought-tolerance high-yielding varieties against climate effects on Aus and Aman rice varieties.

\section{Introduction}

Various factors influence crop rice production globally, e.g., climate and technological advancement, genetics, agronomic, irrigation practices, resource management systems, and usage of fertilizer applications, and these elements vary from country to country (Mishra et al. 2015; Huang et al. 2017; Kukal and Irmak 2018). One of the most significant aspects of crop output is the climate. It has been stated that the current trends in change of climatic elements might be in charge of altogether influencing yield trends regardless of progress in technology. The Fifth Assessment Report (IPCC 2013) pointed out that the past century has encountered an expansion of $0.74^{\circ} \mathrm{C}$ temperatures globally. These increases have had impressive temporally and spatially variable impacts on agricultural rice production globally (Peng et al. 2004; Lobell et al. 2011). Numerous studies demonstrate that climate change has had an adverse outcome on crop yields generally (Ray et al. 2012; Arunrat et al. 2020) and will significantly impact crop production in the coming years globally (Lobell et al. 2008). Moreover, climate-driven rice yield relationships are scale-reliant, long statistical datasets at the area level are critical for exploring reaction patterns of rice yield to climate change and variability (Lobell et al. 2008; Islam et al. 2020a). However, the consequences of climate change on crop yields in Bangladesh are quite different from those investigations (Yu et al. 2010; Raune et al. 2013; Mottaleb et al. 2017; Islam et al. 2019; Zinat et al. 2020).

Although many studies on the trend analysis of climatic components in Bangladesh have been observed in recent years (Rahman et al. 2017; Zannat et al. 2019; Dina and Islam 2020; Ghose et al., 2021a, b), but few comprehensive studies have been undertaken on climatic trends concerning rice yield under changing the climate (Aman et al. 2015; Sarker et al. 2019; Islam et al., 2020a). It is imperative to conduct researches on a local or territorial scale due to the significant regional variations in air temperature (Basak et al. 2010; Mottaleb et al. 2015) and rainfall patterns (Rahman et al. 2017). The IPCC (2013) report underlines the need for regional or district-level information on climate change. Such initiatives can help meet policymakers' information needs at the national level and diverse economic groups. There is a deficiency of quantitative rice yield data on climate change impact, particularly local region-specific. These specific gaps exist in dataset information concerning Bangladesh. This offers one-of-a-kind chances to investigate if the climatic effects on rice yield are a function of a climatic component at a regional / district level, which is not clearly and adequately addressed in the past literature. Given the importance of this issue, this study devises to understand climatic trends for rice yield, with a specific focus on spatiotemporal variations and how such variations impact rice production in various copping seasons and agro-economic zones.

The northwest (NW) region is vital for the rice production hub. This region has a complex hydro-geographic setting and considerable spatial and temporal variations in environmental and rice formative elements (Sarker et al. 2014; 2019; Islam et al. 2017; Salam et al. 2019; Zinat et al., 2020) and region's significant contribution to national rice production and food security 
(Ghose et al. 2021a). Rice production and yield mainly depend on climatic variability, and hazardous events like floods and droughts can harm rice yield. The climatic elements such as rainfall, temperature, humidity, and sunshine are the factors for agricultural and rice crops (Yu et al. 2010). Seasonal climate may influence food security by changing the variability of rice yields in various locations of northwest Bangladesh (Ara et al. 2016). In the present investigation, the northwest region incorporates sixteen districts, contributes up to $40 \%$ of the national rice production, and grows many other yield types (BBS 2017; Kamruzzaman et al. 2019).

The northwest region of Bangladesh has been chosen as a study area to contribute to rice production demand and gain a better understanding of climatic variation in Bangladesh. Because some scientific questions should be routed to policymakers at the regional/district and local levels to enhance scientific knowledge of the climate-rice yield dynamics, which can result in improved rice production practices as a result of changing climate variables:

1. What climatic factors (temperature, rainfall, humidity, and sunshine hour) influence rice yield variation spatially and temporally?

2. What is the nexus between climatic variables and rice yield under diverse climates in northwest Bangladesh?

3. What are the regional effects of climate change on rice yield variation?

This paper presents broad datasets to respond to the three questions mentioned above in Bangladesh's northwest region during the study period. First, this paper focuses on three important rice, specifically Aus, Aman, and Boro rice crops, to demonstrate the spatial and temporal variations of climatic variables with rice yield using a statistical approach and Geographic information system (GIS) applications. In contrast, the earlier study investigates the rice yield variability followed by wheat at the national level (Amin et al. 2015). Second, this paper concentrates on the association between climatic elements and rice yield of three major rice ecotypes under climate change using the linear and non-linear trends. The earlier published works did not recognize humidity and sunshine hour as climatic elements even though these elements potentially impact rice yield. Besides, climate variables and their effect, to examine the impact of all other relevant variables such as irrigation, fertilizer, and pesticide uses are outside the scope of the present study. This research will assist in the development of appropriate agro-adaptive procedures to mitigate rice yield reductions linked to climate change.

\section{Data And Methods}

\subsection{Study area and rice culture description}

The northwestern part of Bangladesh, covering the greater Rangpur and Rajshahi divisions, is displayed in Fig. 1. It is located between $23^{\circ} 47^{\prime}$ to $26^{\circ} 38^{\prime}$ North Latitude and $88^{\circ} 02^{\prime}$ to $90^{\circ} 01^{\prime}$ East Longitude. Two major meander river systems have cut their path through the study area, Brahmaputra-Jamuna in the east and Ganges-Padma in the south (Islam et al., 2020b). Another minor but crucial transboundary river Teesta flows through the northern part, playing a vital role in the agriculture of some northern districts (Rahman and Islam, 2019; Islam et al. 2021). Rice is vigorously cultivated throughout the area in three seasons.: Aus season, March to August; Aman season, June to November; and Boro season, December to May (BBS 2017). These cultivating times are almost adjusted with three main climatic seasons, namely the hot summer (March-May), monsoon season (July-October), and the winter season (December-February). Supplementary irrigation is required by Aus rice during the primary phase of its rising period; in contrast, availability of rainfall and supplemental irrigation during months of monsoons play a pivotal role in Aman rain-fed rice type in planting time. In contrast, hot summer and dry winter is the condition of Boro rice, as it is thoroughly rinsed. Only $8 \%$ of Aus and $5 \%$ of Aman rice are irrigated (Sarker et al. 2019).

\subsection{Data sources and quality control check}

Rice yield datasets of Aus, Aman, and Boro rice (mt/ha) in the timeline 1976-2015 were acquired from the yearbook of agricultural statistics published by the Bangladesh Bureau of Statistics (BBS 2017) during the study period. Daily climatic datasets, including rainfall, temperature, humidity, and sunshine were collated from the Bangladesh Meteorological Department (BMD) from 1976 to 2015 (http//.www.bmd.gov.bd). It is worth mentioning that although BMD runs 35 meteorological stations 
in Bangladesh, only six meteorological stations are homogeneously distributed in the northwest region. This study's data series covers over 40 years, and it is worth testing for stationarity (Chen et al. 2004; Uddin et al. 2020). As a result, this requirement implies a detailed study of the datasets to ensure they are stationary before estimating the regression model and performing modified Mann-Kendall (MMK) test trend analyses. As such, we applied an augmented Dickey-Fuller (ADF) test (i.e., the presence of unit roots for each variable) (Dickey and Fuller 1979), the outcomes of which are summarized in Table S1. Aman and Boro rice crop yields are combined on a first-order basis, I(1), implying that the series is non-stationary. These two rice varieties contribute $80 \%$ of rice production in Bangladesh. However, Aus yield and all of the climate variables for all rice-growing seasons are integrated of order zero, I(0); thus, these data series are static in their level method. Nevertheless, before computing, the variables with I(1) were differenced (McCarl et al. 2008), as not all variables are integrated in a similar order.

Correlation coefficients between rice yield and other climatic variables were evaluated for quality control to rationalize the overall implications of this difference in climatic data and rice yield datasets in the study site. It is evident from the correlation coefficients between rice yield and other climatic variables that yield is mainly dominated by rainfall and temperature. In contrast, humidity and sunshine have slight influences on rice yield (Fig. 2). It is noted that minor quality deviation would not affect the calculated rice yield data quality. When applied to autocorrelation time-series data, nonparametric trend tests such as modified Mann-Kendall produce inaccurate or excessive rejection rates (Li et al. 2018). In this regard, all data utilized as a part were initially checked at a $5 \%$ significance level for the autocorrelation coefficient. It is observed that the distinct yearly data sets of every rice growing seasons were free from autocorrelation of a significant level. Figure 2 shows that all variables are significant at a $95 \%$ confidence level.

\subsection{Multiple linear regression modeling}

The dependent parameters of the present research were the yield of three majors, e.g., Aus, Aman, and Boro rice ecotypes, and the independent parameters such as four climatic variables (mean temperature, rainfall, humidity, and sunshine hour). The critical distinction was that the growing season, which varies according to crop, is the optimal time to see the causal impacts of climate change on the yield of these rice types (Lobell et al., 2008; Amin et al., 2015). Multiple linear regression modeling was adopted to estimate the relationships between climate parameters and crops yields of rice crops under the investigation at the regional level. Based on the characteristics of dependent parameters and intrinsic autocorrelation that occurred among the independent parameter, we applied the Heteroskedasticity and Autocorrelation (HAC) reliable standard error and Feasible Generalized Least Square (FGLS) were the most appropriate technique compared to Ordinary Least Square (OLS) technique (Cochran and Orcutt, 1949; Newey, and West, 1987). Accordingly, the following Eq. (1) for multiple linear regression (MLR) modeling was adopted for the chosen three major rice crops.

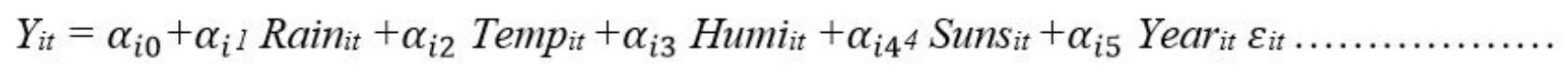

where, $\mathrm{Y}=$ yield $(\mathrm{M} . \mathrm{t} / \mathrm{ha})$ of respective rice crops

$\operatorname{Temp}_{\mathrm{t}}=$ Growing season average daily temperature $\left({ }^{\circ} \mathrm{C}\right)$

Rain $_{\mathrm{t}}=$ Growing season total daily rainfall $(\mathrm{mm})$

Humi $_{\mathrm{t}}=$ Growing season average daily humidity (\%)

Suns $_{\mathrm{t}}=$ Growing season average daily sunshine (hours/day)

$\mathrm{t}=$ time (year)

$\varepsilon=$ Error term

In all cases, the prior probability is that the rice crops grown for food require a particular setting to persist, including the optimal temperature, soil moisture condition, relative humidity, and sunshine hours. A fluctuating climatic condition can have both advantageous and detrimental effects on rice ecotypes. As the mean temperature rises, it improves crop growth and production 
by increasing photosynthesis, increasing agricultural output (Sombroek et al. 2014). In contrast, enormously high-temperature influences adversely metabolic process of plant growths, such as the constancy of different proteins and membranes and the efficiency of enzymatic reactions in the plant cell, which reasons denaturation and ultimately metabolic inequality. Hightemperature tremors may reduce photosynthetic rates by influencing photosystem II and Rubisco tasks and thus impeding rice yield (Islam et al. 2020a). However, extremely low temperatures may trigger threatening injury in the plant growth stage (Bhandari and Nayyar 2014). Rainfall enhances rice yield definitely by freely dissolving the nutrients for soil absorption by plants (IPCC 2013). On the other aspect, excessive rain during the rainy monsoon season can result in soil erosion or wash-out and nutrient depletion at the soil surface due to fast runoff. Similarly, farmers may experience rice production losses because of inadequate and unpredictable rainfall during the monsoon season (Ghose et al. 2021a).

Similarly, high or low humidity is unfavorable for elevated rice yield. When appropriate humid air prevails, rice crops always tend to absorb soil nutrients for optimal yield. Relative humidity governs the plant-water connection indirectly and affects leaf growth, photosynthesis, disease incidence, and eventually rice yields. Additionally, atmospheric dryness can significantly jeopardize dry matter crop productivity via stomata regulation and leaf water potential (Amin et al. 2015). Through photosynthesis, sunshine ultimately influences crop growth rate and blooming stage. Solar radiation is required for plants to generate food, sustain in the long run, and function fully. However, excess sunshine depicts similar negative impacts on rice crops, identical to high-temperature stress conditions. Therefore, variations in climate would be possible to have different substantial effects on rice crops.

\subsection{Statistical analyses}

Spatial analysis was performed using Inverse Distance Weighting (IDW) interpolation (implemented in ArcGIS 10.5). Among the available interpolation models, the inverse distance weighted (IDW) approach was preferred for spatial evaluation in this work because of its convenience of use and estimate precision relative to other interpolation models such as kriging (Praveen et al. 2020; Islam et al. 2020b; 2021). This approach is pre-installed on the ArcGIS platform. The primary reason for choosing the IDW model is because it rapidly and accurately computes spatially interpolated values.

The modified Mann-Kendall (MMK) test, a widely suggested nonparametric test (Mann 1945; Kendall 1975), was used in this study to examine temporal patterns in yield and related climatic data (Islam et al. 2020b; Zinat et al. 2020). This MMK test was chosen because it takes seasonality and autocorrelation into account within the time series and avoids significant autocorrelations of more than one lag in time series trend detection. To determine the slopes of yield trends and climate variables, Theil-Sen's Slope estimator (Sen 1968) was employed. This is a widely used approach for determining the slope magnitude of a trend line. When a variation in a time series is apparent but cannot be identified to a reasonable degree using statistical tests, Theil-Sen's Slope estimator produces more accurate data (Radziejewski and Zbigniew 2004; Rahman et al. 2017; Salam et al. 2019). The method was successfully applied to determine the magnitude of Bangladesh's time series of climatic variables trends. In this study, the nonparametric approach of Theil-Slope Sen's is utilized to determine the actual slope of an existing trend (as a change per unit time) that is expected to be linear.

\section{Results}

\subsection{Descriptive statistics}

Table 1 summarizes rice yield information. The fundamental characteristics of rice yield and climatic variables (rainfall, temperature, humidity, and sunshine) over 40 years in northwestern Bangladesh are illustrated in Table 1. The highest total seasonal rainfall ( $\mathrm{mm}$ ) and humidity (\%) are observed in the Aman yield and the lowest in Boro yield. The highest temperature was observed in the Aus yield and the lowest in Boro yield. The sunshine (hr/day) period is the highest in Boro rice-growing season than others. However, climatic variables affecting rice output and growing season vary in northwestern Bangladesh. 
Table 1

Descriptive statistics of climatic variables during the study period.

\begin{tabular}{|c|c|c|c|c|c|c|c|}
\hline \multirow[t]{2}{*}{ Variables } & \multirow{2}{*}{$\begin{array}{l}\text { Major } \\
\text { Crops }\end{array}$} & \multicolumn{6}{|l|}{ Statistics } \\
\hline & & Mean & Std. Deviation & Minimum & Maximum & Skewness & Kurtosis \\
\hline \multirow[t]{3}{*}{ humidity } & Aus & 75.9304 & 2.55491 & 67.72 & 81.31 & -0.632 & 1.391 \\
\hline & Aman & 81.4639 & 3.04139 & 66.14 & 84.83 & -3.486 & 16.463 \\
\hline & Boro & 71.6868 & 3.77558 & 56.83 & 77.28 & -1.627 & 4.836 \\
\hline \multirow[t]{3}{*}{ Rainfall } & Aus & 1358.2740 & 267.33837 & 814.00 & 2034.58 & 0.193 & -0.059 \\
\hline & Aman & 1457.2667 & 297.98415 & 905.00 & 1989.50 & 0.036 & -0.806 \\
\hline & Boro & 419.8521 & 260.30103 & 133.83 & 1404.17 & 2.285 & 5.436 \\
\hline \multirow[t]{3}{*}{ Sunshine } & Aus & 6.2597 & 0.50812 & 5.19 & 7.87 & 0.840 & 1.379 \\
\hline & Aman & 5.8713 & 0.54104 & 5.03 & 7.30 & 0.886 & 0.709 \\
\hline & Boro & 7.2628 & 0.69083 & 5.45 & 8.95 & -0.261 & 0.478 \\
\hline \multirow[t]{3}{*}{ Temperature } & Aus & 27.9325 & 0.93419 & 26.03 & 31.78 & 2.034 & 8.313 \\
\hline & Aman & 27.3720 & 0.71622 & 25.87 & 30.14 & 2.515 & 9.296 \\
\hline & Boro & 22.8804 & 1.74108 & 21.67 & 32.52 & 4.753 & 25.371 \\
\hline
\end{tabular}

\subsection{Spatial variability and trends assessment}

We adopted the coefficient of variation (CV) to highlight spatial variations, which is yield variability corrected for mean yields. Figure 3 presents the seasonal variability (CV) of rice yields for the studied region. The highest variability existed across Nilphamari and Bogra regions for the Aus yield, and relatively low variability existed in Dinajpur and Rajshahi regions. For Aman yield, relatively high CV \% represents more significant relative variability in Nilphamamari, Rangpur, Dinajpur, and Pabna regions than Bogra and Rajshahi regions. Boro showed the lowest magnitude of $\mathrm{CV}$ among all three crops except for the Rangpur region.

Trends in rice yield from 1976-2015 on a regional scale are also illustrated in Fig. S1. All three rice ecotypes, including Aus, Aman, and Boro had a positive yield trend for all regions except for Boro yield in the Pabna region. The highest Aus yield trend was found in Rangpur, Rajshahi, and Pabna regions at the rate of $1.3 \mathrm{~m} . \mathrm{t} / \mathrm{ha} / \mathrm{decade}$. Similarly, the highest Aman yield trend was observed in Nilphjamari, Bogra, and Pabna regions at the rate of $0.72 \mathrm{~m} . \mathrm{t} / \mathrm{ha} / \mathrm{decade}$. The highest Boro yield trend was detected in Nilphamari and Rangpur regions at the rate of $0.45 \mathrm{~m} . \mathrm{t} / \mathrm{ha} / \mathrm{decade}$. The $\mathrm{CV}$ of rainfall varies in different seasons (e.g., Aus, Aman, Boro), where temperature shows high variability in Rajshahi and Bogra regions and relatively low variability in Nilphamari and Pabna regions for Aus and Aman yield except for Rajshahi regions (Fig. 3). The highest CV for humidity in the Nilphamari region and the lowest in the Dinajpur region for almost all rice-growing seasons. In contrast, the highest CV for sunshine in Nilphamari and Bogra regions and the lowest in the Rangpur region.

The trends revealed in rainfall, temperature, humidity, and sunshine during the rice-growing seasons for the study period in NW Bangladesh are represented in Fig. 4. Rangpur, Dinajpur, and Nilphamari stations represent positive trends, while Bogra, Rajshahi, and Pabna stations showed negative rainfall trends for all rice-growing seasons. The highest positive trend was observed at the rate of $86 \mathrm{~mm} /$ decade in the Nilphamari region. In contrast, the highest negative trend was $-96 \mathrm{~mm} / \mathrm{decade}$ in Bogra, Rajshahi, and Pabna regions, both for Aman and Aus rice yields. Temperature mainly showed positive trends for all ricegrowing seasons except for Nilphamari and Dinajpur regions of Aus and Boro rice yield. A negative trend of $-0.29^{\circ} \mathrm{C} / \mathrm{decade}$ was identified in the Dinajpur region for Boro. In contrast, a positive trend of $0.25^{\circ} \mathrm{C} /$ decade was detected in Bogra, Rajshahi, and Pabna regions for Aus and Rangpur regions for Aman. The highest positive humidity trend of $4.03 \% /$ decade was observed for 
Aus and Boro, while the highest negative humidity trend $-0.83 \% /$ decade was detected in Rangpur and Bogra regions for Aman. Sunshine represented all negative trends for all rice-growing seasons, where the highest negative trend was observed at the rate of $-83 \mathrm{hrs} /$ decade in the Rangpur region for Boro yield.

\subsection{Temporal variability and trends analyses}

During the Aus and Aman rice-growing seasons, Rainfall exhibited a generally rising trend with noticeable and significant changes (Fig. S2). There was no consistent pattern in the Boro rice season over time, but the variations would affect the trend because it depends on groundwater conditions infiltrated by rainwater. On the other hand, the temperature changed a lot, and the overall tendency during the Aus and Aman seasons was upwards. Slight variations in Boro rice yield temperature were observed; nevertheless, the tendency looked to be increasing. Humidity also trended upward with minor variances across the rice-growing seasons. On the other hand, Sunshine demonstrated a declining tendency throughout the seasons, with more significant variability.

Table 2 shows that MMK test $Z$ values of Rainfall and Sunshine were decreased in Aus, Aman, and Boro seasons compared to the increased $Z$ values of temperature and humidity. However, Sunshine represents the lowest MMK Z values than other variables in this study. Sen's slope estimator results show that Rainfall and Sunshine are experiencing significant downward trends at the rate of $-6.374 \mathrm{~mm} /$ year and $-0.026 \mathrm{hr} /$ year for Aus, $-5.934 \mathrm{~mm} /$ year and $-0.019 \mathrm{hr} /$ year for Aman, -1.428 $\mathrm{mm} /$ year, and $-0.056 \mathrm{hr} /$ year for Boro respectively. In contrast, temperature except for Boro, humidity, and yield are experienced significant upward trends for all rice-growing seasons at the rate of 0.014 to 0.014 /year, 0.001 to $0.196 \%$ /year, and 0.030 to $0.056 \mathrm{M} . \mathrm{t} /$ year respectively. Boro temperature showed a slight downward trend of -0.003 /year.

Table 2

The outcomes of non-linear trend of variations in rice yield and climatic variations in the study area

\begin{tabular}{|llllllllll|}
\hline Tests & \multicolumn{2}{l}{ MMK Z-Value } & \multicolumn{3}{c|}{ Sen's-Slope $\boldsymbol{\beta}$} & \multicolumn{7}{c|}{$\boldsymbol{p}$-Value } \\
\hline Rice ecotypes & Aus & Aman & Boro & Aus & Aman & Boro & Aus & Aman & Boro \\
\hline Rainfall(mm) & -2.027 & -1.247 & -1.060 & -6.374 & -5.934 & -1.428 & 0.043 & 0.213 & 0.289 \\
\hline Temperature $\left({ }^{\circ} \mathrm{C}\right)$ & 2.109 & 2.774 & -0.583 & 0.014 & 0.014 & -0.003 & 0.035 & 0.006 & 0.560 \\
\hline Humidity (\%) & 2.796 & 0.012 & 3.845 & 0.115 & 0.001 & 0.196 & 0.005 & 0.991 & $<0.001$ \\
\hline Sunshine(hr/day) & -3.892 & -3.228 & -6.735 & -0.026 & -0.019 & -0.056 & $<0.001$ & 0.002 & $<0.001$ \\
\hline Yield (M.t/ha) & 7.868 & 7.609 & 8.334 & 0.030 & 0.032 & 0.056 & $<0.001$ & $<0.001$ & $<0.001$ \\
\hline
\end{tabular}

\subsection{Climatic variability on regional yield}

Figure 5 represents the climatic variability of rainfall $(\mathrm{mm})$, temperature (oC), humidity (\%), and sunshine (hr/day) from 1976 to 2015 in the study region. The Rangpur region has the highest, and the Rajshahi region has the lowest annual Rainfall ( $\mathrm{mm}$ ). In contrast, the Rajshahi region has the highest and the Rangpur region's lowest average temperature). Humidity (\%) is the highest at Rangpur and the lowest in the Dinajpur region. The Sunshine period (hr/day) was observed as the highest at Rangpur and the lowest in the Pabna region.

The impacts of climatic parameters like rainfall, temperature, humidity, and sunshine have been analyzed using the linear mixed model for each rice type during 1976-2015. The results show the rainfall, temperature, humidity, and sunshine effects Aus, Aman, and Boro yields in Bangladesh at the regional scale (Table 3). Here, the significance of the trend for humidity was the highest for the Boro rice and insignificant for Aman rice. Again, rainfall showed the highest trend value in the Boro and the lowest in the Aus and Aman, respectively. Here, sunshine presented the strong significance of trend for all major crops. In terms of temperature, the trend was most significant for Aus and Aman rice $(p<0.01)$ and insignificant for Boro rice $(p>0.001)$. 
Table 3

The outcomes of the linear trend model of variations in climatic variables for the study period

\begin{tabular}{|c|c|c|c|c|c|c|}
\hline $\begin{array}{l}\text { Major } \\
\text { Crops }\end{array}$ & Climate & Intercept & Coefficient for time (Trend) & $\mathrm{t}$-value & p-value & $\mathbf{R}^{2}$ \\
\hline & Humidity & -99.54 & $0.09 \star \star$ & 2.71 & 0.010 & 0.16 \\
\hline & Rainfall & 16075.00 & $-7.38 * \star$ & -2.10 & 0.042 & 0.10 \\
\hline \multirow[t]{4}{*}{ Aus Rice } & Sunshine & 57.72 & $-0.03^{\star \star \star}$ & -4.55 & 0.000 & 0.35 \\
\hline & Temperature & -55.26 & 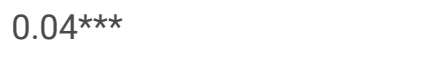 & 3.77 & 0.001 & 0.27 \\
\hline & Humidity & -20.70 & 0.05 & 1.24 & 0.224 & 0.04 \\
\hline & Rainfall & 9915.70 & -4.24 & -1.04 & 0.305 & 0.03 \\
\hline \multirow[t]{4}{*}{ Aman Rice } & Sunshine & 57.60 & $-0.03 * \star \star$ & -4.17 & 0.000 & 0.31 \\
\hline & Temperature & -35.55 & $0.03^{\star \star \star}$ & 3.70 & 0.001 & 0.26 \\
\hline & Humidity & -273.93 & $0.17 * \star \star$ & 3.92 & 0.000 & 0.29 \\
\hline & Rainfall & -18309.00 & $9.39 * \star \star$ & 2.87 & 0.007 & 0.18 \\
\hline \multirow[t]{2}{*}{ Boro Rice } & Sunshine & 100.21 & $-0.05^{\star \star \star}$ & -7.90 & 0.000 & 0.62 \\
\hline & Temperature & -67.34 & $0.05^{\star}$ & 1.96 & 0.057 & 0.09 \\
\hline
\end{tabular}

The outcomes of the MLR model analysis for rice yield and climatic variables are summarized in Table 4. The coefficients for the effects of humidity and Rainfall on Aus rice yield are negative, but the coefficients for the effects of Sunshine and temperature are positive. The adjusted $\mathrm{R}^{2}$ value indicated that climate conditions account for $67 \%$ of the variation in Aus yield. 
Table 4

Results of multiple linear regression model analysis for rice yield and climatic variables.

\begin{tabular}{|c|c|c|c|c|c|c|c|c|c|}
\hline & Aus & & & Aman & & & Boro & & \\
\hline & Coefficient & S.E. & ${ }_{\text {value }}$ & Coefficient & S.E. & $\begin{array}{l}\mathrm{t} \\
\text { value }\end{array}$ & Coefficient & S.E. & $\begin{array}{l}\mathrm{t} \\
\text { value }\end{array}$ \\
\hline Humidity & -0.00718 & 0.00928 & -0.77 & -0.00053 & 0.00279 & -0.19 & -0.00685 & 0.00483 & -1.42 \\
\hline Rainfall & -0.00002 & 0.00007 & -0.23 & $-0.00005^{\star}$ & 0.00003 & -1.73 & 0.00008 & 0.00007 & 1.08 \\
\hline Sunshine & 0.02608 & 0.04215 & 0.62 & 0.00750 & 0.02007 & 0.37 & $-0.08254^{\star *}$ & 0.03642 & -2.27 \\
\hline Temperature & 0.01768 & 0.02562 & 0.69 & $0.02418 *$ & 0.01350 & 1.79 & 0.00000 & 0.01029 & 0.00 \\
\hline Trend & 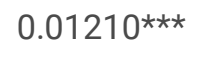 & 0.00240 & 5.05 & 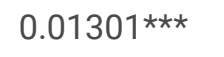 & 0.00090 & 14.40 & 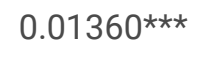 & 0.00213 & 6.39 \\
\hline Intercept & $-23.73474^{\star \star \star}$ & 4.27503 & -5.55 & $-25.83731^{\star \star \star \star}$ & 1.80465 & -14.32 & $-24.83148 * \star \star$ & 4.30693 & -5.77 \\
\hline Model $\mathrm{R}^{2}$ & 0.71 & & & 0.93 & & & 0.85 & & \\
\hline Adjusted $\mathrm{R}^{2}$ & 0.67 & & & 0.92 & & & 0.83 & & \\
\hline$F$ value & 16.78 & & & 90.11 & & & 39.77 & & \\
\hline$P$ value & 0.0000 & & & 0.0000 & & & 0.0000 & & \\
\hline RMSE & 0.10 & & & 0.05 & & & 0.09 & & \\
\hline
\end{tabular}

FGLS tool was applied to identify the impact of the climate parameters on the Aman rice yield. Concerning Aman rice, the adjusted $R^{2}$ value showed that climatic variables explain $92 \%$ of the variation in yield, which strongly supported the climatic impact on this crop. The humidity and rainfall effects on Aman rice yield have negative coefficients, even though the significance level for Rainfall is $10 \%$. On the other hand, sunshine and temperature effects are positive, although temperature exhibited a statistically substantial influence on the yield at the $10 \%$ level.

The HAC technique was used to estimate the climate-Boro rice nexus in the study area. Both humidity and Sunshine negatively affected the Boro rice yield, where Sunshine displayed a statistically significant impact on the yield at the $5 \%$ level. Furthermore, both Rainfall and temperature positively influenced the exact rice yield. The adjusted $\mathrm{R}^{2}$ value demonstrated that climatic parameters account for 83 percent of the variation in Boro yield, thus validating the crop's climatic influence.

\section{Discussion}

This research explores the climatic effects on the rice yield for three rice ecotypes spatiotemporally in northwest Bangladesh using 40-years datasets. A significant difference was observed in the three rice ecotypes in the rice-growing season: rainfall, temperature, humidity, and sunshine. The study demonstrates that climatic factors have a significant impact on rice productivity. For example, temperature fluctuations were highly linked with the rice yield, similar to earlier studies (Sarker et al. 2014; Shahid et al., 2016; Islam et al., 2020a; Jerin et al. 2021; Kamruzzaman et al. 2021). Besides, the results also reveal different climatic influences on rice yield to show the strong regional variations of rice yields in northwest Bangladesh.

Rice yields for several rice varieties showed a distinct regional pattern, with the Aus yield being more favorable in Dinajpur and Rajshahi regions than other regions. However, most of the northern portion of the study area had a low Aus yield. By contrast, Aman was typically grown in the western parts except for the Dinajpur region but low yield in the southern part. Boro had more yield in the central part of the study region and less in scattered areas. Several factors are contributed to rice yield variations across the study area. Natural factors (e.g., topography, soil, drought/flood, and climatic conditions), management factors (e.g., 
irrigation, use of fertilizer/pesticides), and agricultural technologies (e.g., plowing approaches and the use of high yielding varieties and hybrid seed) (Zinat et al., 2020). Rice yields have increased threefold between 1976 and 2015, and Boro yield has grown significantly more than Aus and Aman yields. Boro yield may have expanded due to a shift in Boro production from rainfed to irrigation during the dry season. Sarker et al. (2019) and Ghose et al. (221a) are also reported a similar finding.

In this study, the coefficients resulting from the MLR for each rice type were used to evaluate the expected significance of climatic factors on rice yield. The results demonstrate that sunshine showed strongest significance of trend for all major crops. The MLR model suggests that temperature was the most significant for Aus and Aman rice and insignificant for Boro rice. Here, Rainfall exhibited the highest significance of trend in the Boro, and lowest in the Aus and Aman respectively.

A negative temperature impact on the Aus yield was reported by Ruane et al. (2013); however, this study contradicts the previous research. A significant negative relationship between rainfall and Aman yield was observed, suggesting that Aman yield is the most exposed to climate change among the three rice types due to outrageous climatic occasions like drought and flood in NW Bangladesh (Islam et al. 2017). These results have all around concurred with the outcomes of Amin et al. (2015), where rice yield variability would be high for Aman yield. Temperature demonstrated a statistically substantial positive effect on Boro yield. The prior studies reported the positive impact of minimum temperature on the Boro yield (Sarker et al. 2014) and an adverse effect for maximum temperatures (Rimi et al. 2009; Jhajharia and Singh 2011).

The regional variation of climatic parameters describes the impacts of climates on rice yield (Jhajharia et al. 2014). Rice yield varies in different seasons with the climatic variability (Islam et al. 2021). The significant trends are portrayed by high geographic fluctuation, in both nature and greatness of the trend. High spatial variability was seen in the rainfall trends in the study region. Although the yield rate for all the seasons increased day by day due to overusing chemicals and fertilizers, climatic factors need to be considered for sustainable yield. Ruane et al., (2013) showed that Aman rice yield might reduce in different areas in Bangladesh.

Regarding the contrasting results with Ruane et al. (2013) on rainfall, perhaps this is due to the regional focus of the current paper since the degree of flooding in NW Bangladesh is small compared to other parts of the country. Basak et al. (2010) showed that temperature rises boost Boro yield. Our analysis demonstrates that climate affects regional rice yields and that these effects are not uniform across regions and stations. Boro yield was commonly influenced by irrigation management and the positive impact of climate rather than by rainfall regimes during the dry season (Ghose et al. 2021b).

Our results indicate that production hampers in Aus and Aman's rice triggered by drought and submergence stresses can be lessened considerably in three ways. First, simulated water control in the irrigated field dramatically enhances the production of the Boro rice crop, which is the main crop in the country. Thus, artificial floodwater management should be implemented to protect Aus and Aman crops, and additional irrigation should be added in the event of a drought. Second, by developing improved crop rice varieties that are more tolerant of abiotic pressures and incorporating them with current agricultural management systems, such as sowing date changes, short-duration rice varieties developed to avoid drought seasons, and the use of appropriate farm machinery for rapid harvesting, losses in these rice production can also be lowered (Mishra et al. 2015). Ultimately, newly introduced drought and flood-tolerant rice varieties can lessen losses in rice production noticeably (Mottaleb et al., 2015).

The limitation of taking the total rainfall over the season as the parameter analyzed. In NW Bangladesh, rainfall distribution across the season can vary widely and have distinct effects on rice yield. A crop that receives $300 \mathrm{~mm}$ of rainfall in a season that all falls early will have a lower yield than a crop that receives $300 \mathrm{~mm}$ of rain well-distributed across the season. The future study should be focused on the prediction of rice yield with climatic variability in Bangladesh. The findings of this study can benefit regional supervisors and decision-makers in developing region-specific adaptive strategies and address food security in Bangladesh by demonstrating the possible risk associated with climate variations. As a result, our study strongly encourages policymakers and significant sponsors to invest in the research, development, and dissemination of novel rice varieties that are more resilient to drought and other abiotic pressures. 


\section{Conclusion}

The purpose of this research is to explore the effects of climate change on the yield and variability of three major rice ecotypes by utilizing time-series datasets and multi-statistical modeling techniques. The HAC and FGLS techniques were adopted to justify the aim of the study. The outcomes show that the effects of climate variables differ among the three rice varieties. This demonstrates that rainfall is becoming a more significant threat to Aman. Climate variables such as temperature and humidity were the most influential on Aus and Aman rice production in northwestern Bangladesh. In contrast, the sunshine effect was the most influential on Boro rice production with those two variables. Sunshine showed positive interrelation with Aus and Aman rice regarding both yields with a statistically significant negative contribution to Boro rice yield only. However, rain-fed Aman will show greater variability than the other two crops: Boro and Aus. Furthermore, these findings offer additional evidence regarding the possible production losses that will arise from future changes in climate variables. Additionally, most regional dummy variables are statistically significant, implying that they have differential spatial effects on rice yield. This demonstrates how climate change affects different climate zones differently. Hence, the severity of climate change effects on rice crops will fluctuate among the climate zones, and so will the consequence on rice yields. The findings suggest that adaptation plans targeted to specific regions or climate zones should be developed. This highlights the importance of conducting the further location-specific investigation on climate change and agricultural production. Our study will allow for the formation of local or micro-level adaptation programs to crop yield variability, maintain food security, and reduce rural poverty due to climate change.

\section{Declarations}

\section{Acknowledgement}

The authors would like to express their gratefulness to the Bangladesh Meteorological Department (BMD) and the Bangladesh Bureau of Statistics (BBS) for sharing data for this research. We would also like to extend our thanks to the Department of Disaster Management, Begum Rokeya University, Rangpur for providing valuable support during this study. The authors extend their appreciation to the Deanship of Scientific Research at King Khalid University for funding this work through Research Group under grant number (R.G.P.2 /194/42).

\section{Ethical approval}

Not applicable

\section{Consent to Participate}

Not applicable

\section{Consent to Publish}

Not applicable

\section{Data availability}

Data are available upon request on the corresponding author

\section{Code availability}

Not applicable

\section{Author contributions}

A.R.M.T.I., J.M., and M.B.R., designed, planned, conceptualized, drafted the original manuscript, and M.H., and I.A.N, were involved in statistical analysis, interpretation; M.B.R..., A.E., and J.M., contributed instrumental setup, data analysis, validation; 
K.T., A.E., I.A.N., and M.H., contributed to editing the manuscript, literature review, proofreading; J. M., K.T., and A.R.M. T.I., were involved in software, mapping, and proofreading during the manuscript drafting stage.

\section{Conflict of interest}

There is no conflict of interest to publish this work.

\section{Funding statement}

This research was supported by Prince of Songkla University and the Ministry of Higher Education, Science, Research and Innovation, Thailand, under the Reinventing University Project (Grant Number REV64001)

\section{References}

1. Amin MR, Zhang J, Yang M (2015) Effects of climate change on the yield and cropping area of major food crops: a case of Bangladesh. Sustain Sci 7(1):898-915

2. Ara I, Lewis M, Ostendorf B (2016) Spatio-temporal analysis of the impact of climate, cropping intensity and means of irrigation: an assessment on rice yield determinants in Bangladesh. Agriculture Food Security 5(1):1-11

3. Arunrat N, Pumijumnong N, Sereenonchai S, Chareonwong U, Wang C (2020) Assessment of climate change impact on rice yield and water footprint of large-scale and individual farming in Thailand. Sci Total Environ 726:137864

4. Basak JK, Ali MA, Islam MN, Rashid MA (2010) Assessment of the effect of climate change on Boro rice production in Bangladesh using DSSAT model. J Civ Eng 38:95-108

5. BBS (2017) Agricultural Statistical Yearbook of Bangladesh. GoB, Dhaka, Bangladesh

6. Bhandari K, Nayyar H (2014) Low Temperature Stress in Plants: An Overview of Roles of Cryoprotectants in Defense. Available online: http://link.springer.com/chapter/10.1007/978-1-4614-8591-9_9 (accessed on 21 December 2014)

7. Chen C, McCarl BA, Schimmelpfennig DE (2004) Yield variability as influenced by climate: a statistical investigation. Clim Change 66:239-261

8. Dickey DA, Fuller WA (1979) Distribution of the estimators for autoregressive time series with a unit root. J Am Stat Soc 75:427-431

9. Dina RA, Islam ARMT (2020) Assessment of drought disaster risk in Boro rice cultivated areas of northwestern Bangladesh. Euro J Geoscien 2(1):19-29

10. Ghose B, Islam ARMT, Salam R, Shahid S, Kamruzzaman M, Das S, Elbeltagi A, Salam MA, Mallick J (2021b) Rice yield responses in Bangladesh to large-scale atmospheric oscillation using multifactorial model, Theoretical and Applied climatology, DOl: 10.1007/s00704-021-03725-7

11. Ghose B, Islam ARMT, Kamruzzaman M, Moniruzzaman M, Hu Z (2021a) Climate-induced rice yield anomalies linked to large-scale atmospheric circulation in Bangladesh using multi-statistical modeling, Theoretical and Applied climatology, Theor Appl Climatol 144, 1077-1099 DOl: 10.1007/s00704-021-03584-2

12. Huang J, Islam ARMT, Zhang F, Hu Z (2017) Spatiotemporal analysis the precipitation extremes affecting rice yield in Jiangsu province, southeast China. Int J Biometeorol 61(6):1-10

13. IPCC (2013) Climate change 2013: the physical science basis. In: Stocker TF et al (eds) Contribution of Working Group I to the Fifth Assessment Report of the Intergovernmental Panel on Climate Change. Cambridge University Press, Cambridge

14. Isik M, Devadoss S (2006) An analysis of the impact of climate change on crop yields and yield variability. Appl Econ 38:835-844

15. Islam ARMT, Karim MR, Mondol MAH (2021) Appraising trends and forecasting of hydroclimatic variables in the north and northeast regions of Bangladesh, Theoretical Applied climatology, 143(1-2), 33-50, DOI:10.1007/s00704-020-03411-0

16. Islam ARMT, Rahman MS, Khatun R, Hu Z (2020b) Spatiotemporal trends in the frequency of daily rainfall in Bangladesh during 1975-2017. Theor Appl climat 141:869-887

Page $12 / 19$ 
17. Islam ARMT, Shen S, Hu Z, Rahman MA (2017) Drought Hazard Evaluation in Boro Paddy Cultivated Areas of Western Bangladesh at Current and Future Climate Change Conditions, Adv in Meteorol. Article ID 3514381:12 pages

18. Islam ARMT, Shen S, Yang S (2018) Predicting Design Water Requirement of Winter Paddy under Climate Change Condition Using Frequency Analysis in Bangladesh. Agric Water Manage 195:58-70

19. Islam ARMT, Shen S, Yang S, Hu Z, Rahman MA (2020a) Spatiotemporal rice yield variations and potential agro-adaptation strategies in Bangladesh: A biophysical modeling approach, Sustainable Production Consumption, 24, 121-138.

Doi:10.1016/j.spc.2020.07.005

20. Islam ARMT, Shen S, Yang SB, Hu Z, Chu R (2019) Assessing recent impacts of climate change on design water requirement of Boro rice season in Bangladesh. Theor Appl Climatol 138:97-113

21. Jhajharia D, Dinpashoh Y, Kahya E, Choudhary RR, Singh VP (2014) Trends in temperature over Godavari river watershed in southern peninsular India. Inter J Climatology 34:1369-1384

22. Jhajharia D, Singh VP (2011) Trends in temperature, diurnal temperature range and sunshine duration in Northeast India. Int J Climatol 31(9):1353-1367

23. Jerin JN, Islam HM, Islam ARMT, Shahid S, Hu Z, Badhon MA, Chu R, Elbeltagi, A (2021) Spatiotemporal trends in reference evapotranspiration and its driving factors in Bangladesh, Theoretical and Applied climatology, 144, 793-808. DOr: 10.1007/s00704-021-03566-4

24. Kamruzzaman M, Hwang S, Cho J, Jang MW, Jeong H (2019) Evaluating the spatiotemporal characteristics of agricultural drought in Bangladesh using Effective Drought Index. Water 11:2437

25. Kamruzzaman M, Shahid S, Islam ARMT et al. (2021) Comparison of CMIP6 and CMIP5 model performance in simulating historical precipitation and temperature in Bangladesh: a preliminary study, Theoretical and Applied climatology, Springer, SCOPUS/ISI Index, IF: 3.17, DOI: 10.1007/s00704-021-03691-0

26. Kendall MG (1975) Rank correlation methods. Griffin and Co, London

27. Kukal MS, Irmak S (2018) Climate-Driven Crop Yield and Yield Variability and Climate Change Impacts on the U.S. Great Plains Agricultural Production. Sci Rep 8:3450

28. Li M, Chu R, Shen S, Islam ARMT (2018) Dynamic analysis of pan evaporation variations in the Huai River Basin, a climate transition zone in eastern China. Sci Total Environ 625:496-509

29. Lobell DB, Bänziger M, Magorokosho C, Vivek B (2011) Nonlinear heat effects on African maize as evidenced by historical yield trials. Nature Clim Change 1:42-45

30. Lobell DB, Burke MB, Tebaldi C, Mastrandrea MD, Falcon WP, Naylor RL (2008) Prioritizing climate change adaptation needs for food security in 2030. Science 319(5863):607-610

31. Mottaleb KA, Gumma MK, Mishra AK, Mohanty S (2015) Quantifying production losses due to drought and submergence of rainfed rice at the household level using remotely sensed MODIS data. Agriculutral systems 137:227-235

32. Mann HB (1945) Nonparametric tests against trend. Econometrica 13:245-259

33. McCarl BA, Villavicencio X, Wu X (2008) Climate change and future analysis: Is stationary dying? Am. J Agr Econ 90:12411247

34. Mishra AK, Mottaleb KA, Khanal Ar, Mohanty S (2015) Abiotic stress and its impact on production efficiency: The case of rice farming in Bangladesh, Agriculture, Ecosystem and Environment, 199, 146-153

35. MoA (Ministry of Agriculture) (2016) Handbook of Agricultural Statistics

36. Mottaleb KA, Rejesus RM, Mirty MVR, Mohanty S, Li T (2017) Benefits of the development and dissemination of climatesmart rice: ex ante impact assessment of drought-tolerant rice in South Asia. Mitig Adapt Strateg Glob Change 22:879-901

37. Peng S (2004) Rice yields decline with higher night temperature from global warming. Proc. Natl. Acad. Sci. USA 101:99719975

38. Praveen B, Talukdar S, Shahfahad, Mahato S, Mondal J, Sharma P, Islam ARMT, Rahman A (2020) Analyzing trend and forecasting of rainfall changes in India using non-parametrical and machine learning approaches. Sci Rep 10:10342

39. Radziejewski M, Zbigniew WK (2004) Detectability of changes in hydrological records. Hydrol Sci J 49:39-51

Page 13/19 
40. Rahman MA, Yunsheng L, Sultana N (2017) Analysis and prediction of rainfall trends over Bangladesh using Mann-Kendall, Spearman's rho tests and ARIMA model. Meteorol Atmos Phys 129:409-424

41. Rahman MS, Islam ARMT (2019) Are precipitation concentration and intensity changing in Bangladesh overtimes? Analysis of the possible causes of changes in precipitation systems. Sci Total Environ 690:370-387

42. Ray DK, Ramankutty N, Mueller ND, West PC, Foley JA (2012) Recent patterns of crop yield growth and stagnation. Nat Commun 3: 129. doi:10.1038/ ncomms2296

43. Rimi RH, Rahman SH, Karmakar S, Hussain SG (2009) Trend analysis of climate change and investigation on its probable impacts on rice production at Sathkhira, Bangladesh. Pakistan J Meteorol 6:37-50

44. Ruane AC, Major DC, Yu WH (2013) Multi-factor Impact Analysis of Agricultural Production in Bangladesh with Climate Change. Global Environmental Change, vol. 23(1):338-350

45. Salam R, Islam ARMT, Islam S (2019) Spatiotemporal distribution and prediction of groundwater level linked to ENSO teleconnection indices in the northwestern region of Bangladesh, Environment, Development and Sustainability, 22: 45094535

46. Sarker MAR, Alam K, Gow J (2014) Assessing the Effects of Climate Change on Rice Yields: An Econometric Investigation using Bangladeshi Panel Data. Econ Anal Policy 44(4):405-416

47. Sarker MAR, Alam K, Gow J (2019) Performance of rain-fed Aman rice yield in Bangladesh in the presence of climate change. Renew Agric Food Syst 34(4):304-313

48. Sen PK (1968) Estimates of the regression coefficient based on Kendall's tau. J Am Stat Assoc 63:1379-1389

49. Shahid S (2011) Impact of climate change on irrigation water demand of dry season Boro rice in northwest Bangladesh. Clim Change 105(3-4):433-453

50. Shahid S, Wang X-J, Harun SB, Shamsudin SB, Ismail T, Minhans A (2016) Climate variability and changes in the major cities of Bangladesh: observations, possible impacts and adaptation. Reg Environ Change 16(2):459-471

51. Sombroek WG, Gommes R(2014) The Climate Change Agriculture Conundrum: Global Climate Change and Agricultural Production. Direct and Indirect Effects. In FAO Corporate Document Repository; Available online: http://www.fao.orgldocrep/w5183E/w5183e03.htm\#1\%20the\% 20climate (accessed on 10 May 2014)

52. Uddin MJ, Hu J, Islam ARMT, Eibek KU, Zahan MN (2020) A comprehensive statistical assessment of drought indices to monitor drought status in Bangladesh. Arab J Geoscien 13:323

53. Yu WH, Alam M, Hassan A, Khan AS, Ruane AC, Rosenzweig C, Major DC, Thurlow J (2010) Climate Change Risk and Food Security in Bangladesh. Earth Scan, London

54. Zannat F, Islam ARMT, Rahman MA (2019) Spatiotemporal variability of rainfall linked to ground water level under changing climate in northwestern region, Bangladesh. Euro J Geoscien 1(1):35-58

55. Zinat MRM, Salam R, Badhan MA, Islam ARMT (2020) Appraising drought hazard during Boro rice growing period in western Bangladesh. Inter J Biometeorol. Doi:10.1007/s00484-020-01949-2

\section{Figures}




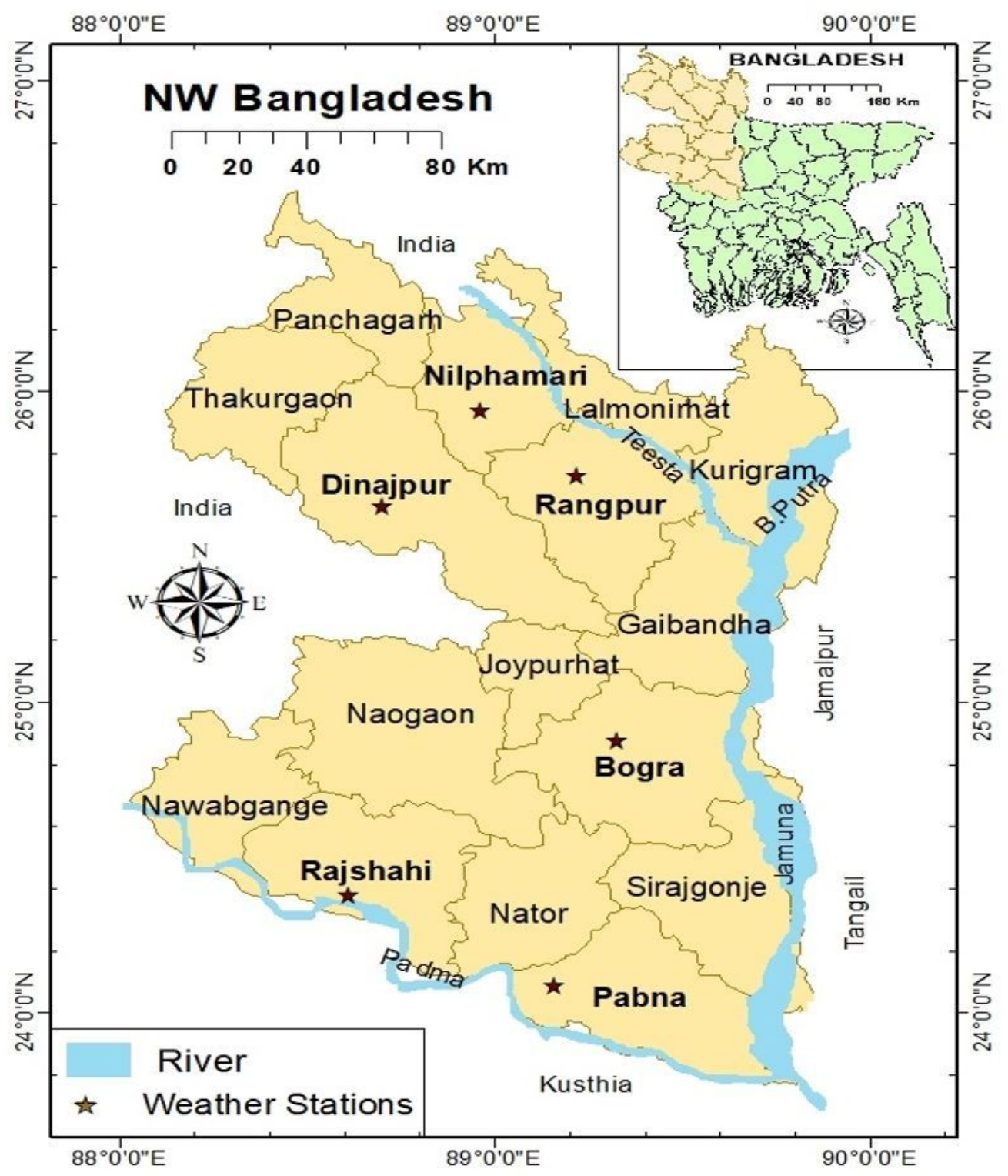

Figure 1

Map showing the study location of northwest Bangladesh and meteorological stations. 

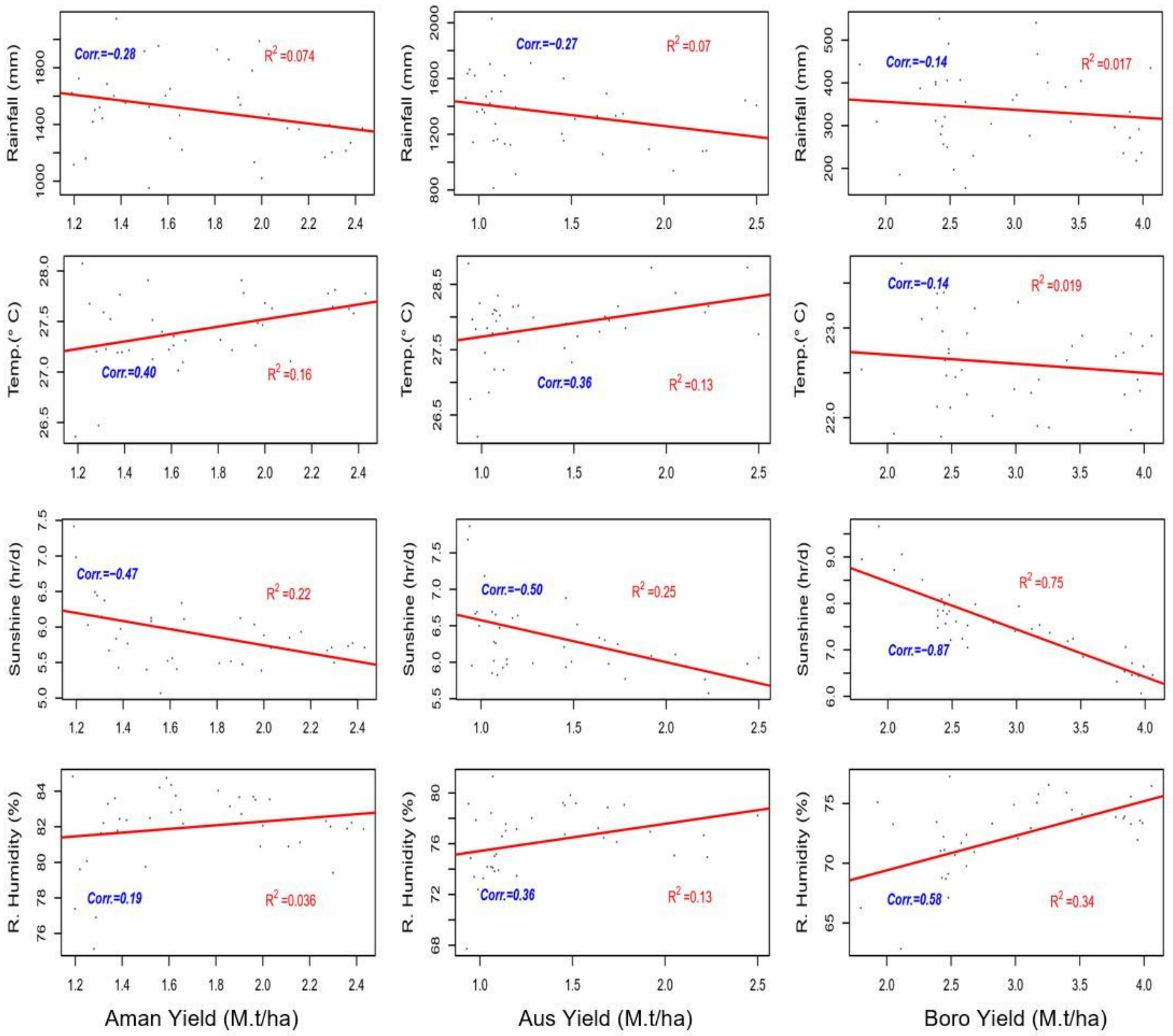

Figure 2

Correlation and linear regression analysis between rice yield and other climatic parameters in the study area during the 19762015. 


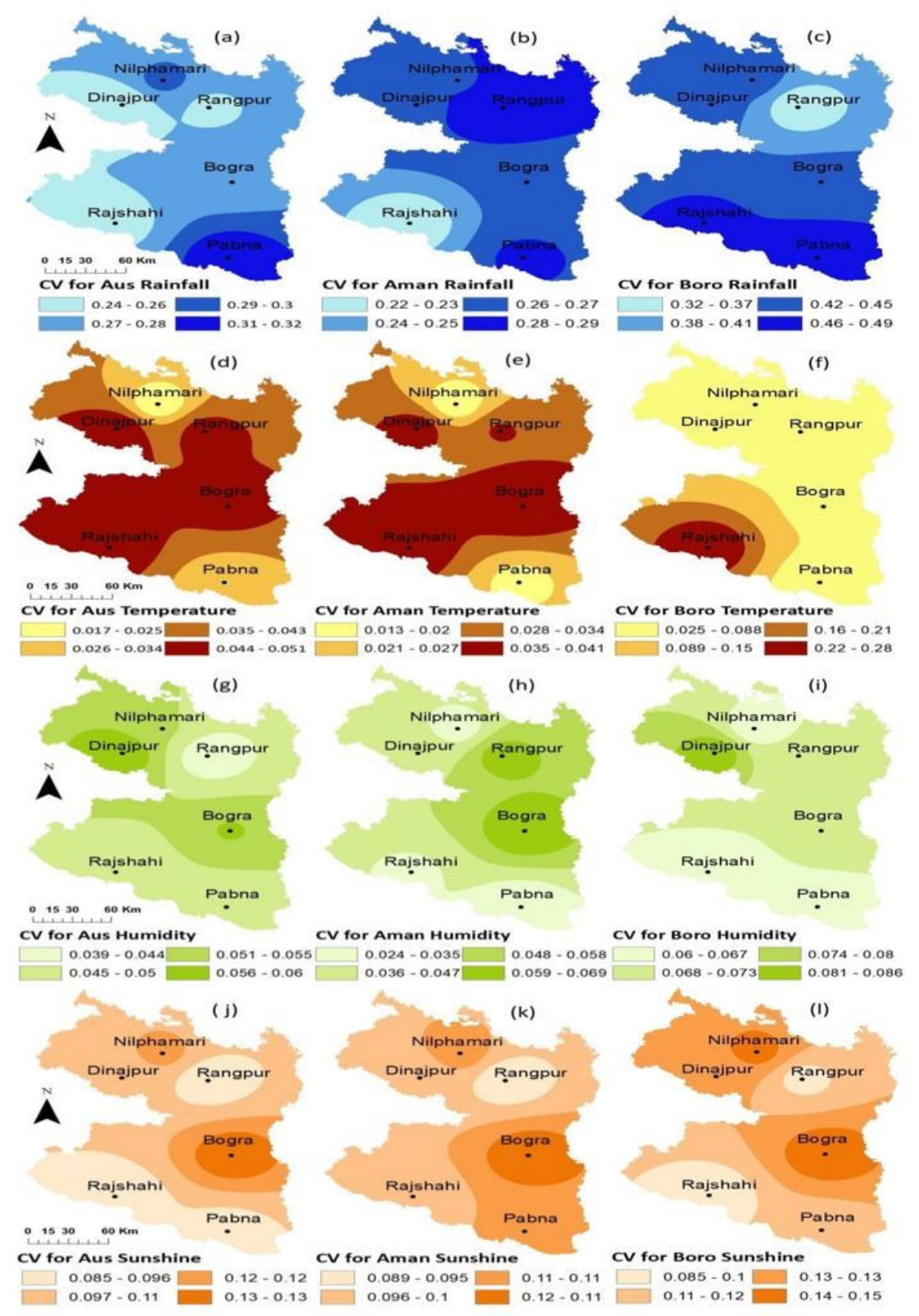

\section{Figure 3}

Coefficient of variation (CV) for (a, b, c) Rainfall (mm), (d, e, f) Temperature $\left({ }^{\circ} \mathrm{C}\right),(\mathrm{g}, \mathrm{h}, \mathrm{i})$ Humidity $(\%)$ and $(\mathrm{j}, \mathrm{k}, \mathrm{l})$ Sunshine (hr) of three rice ecotypes in northwest Bangladesh 


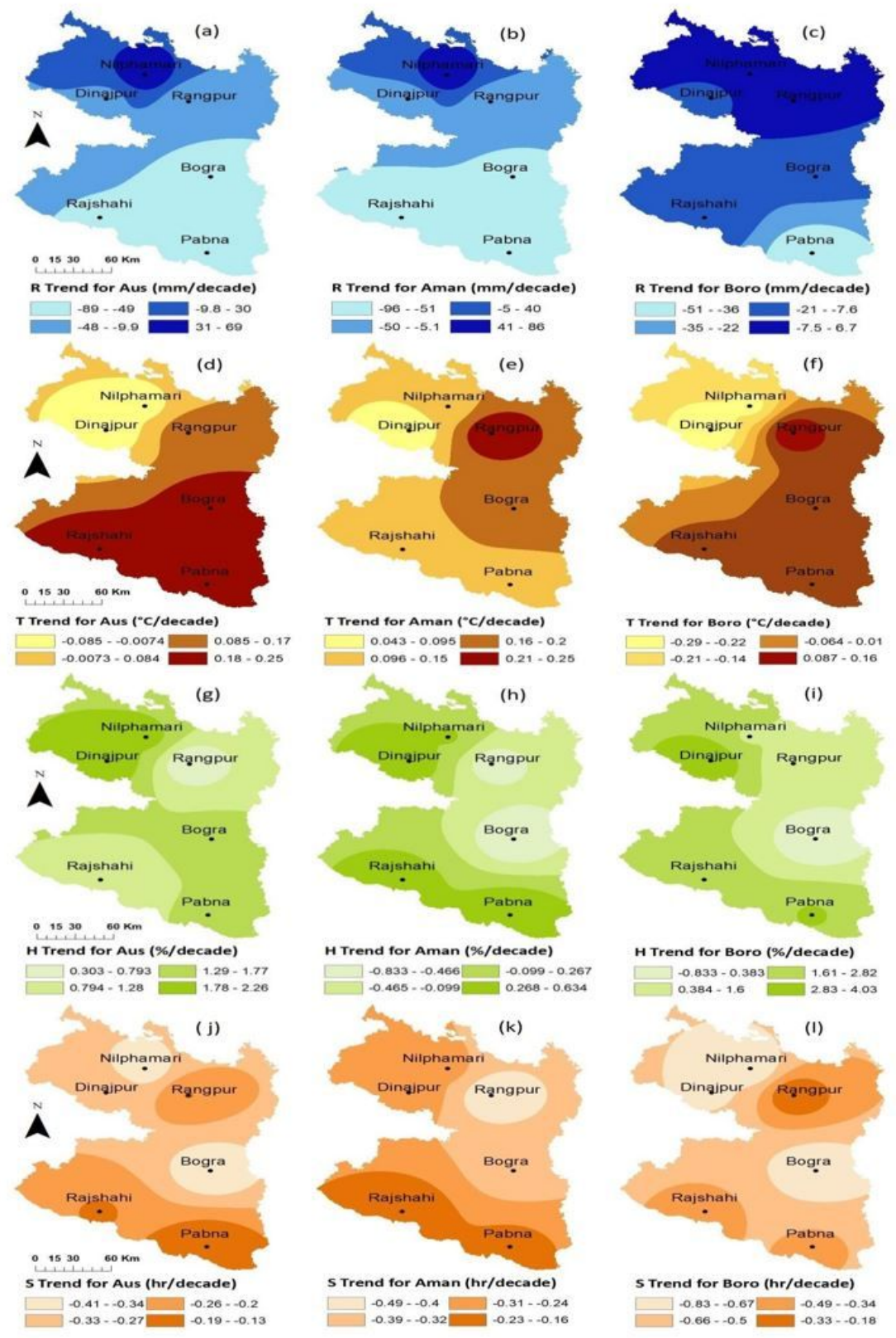

Figure 4

Trends of ( $a, b, c)$ Rainfall ( $m m$ decade- 1$)$, (d, e, f) Temperature ( ${ }^{\circ} \mathrm{C}$ decade- 1$),(g, h, i)$ Humidity (in \% decade- 1 ) and $(j, k, l)$ Sunshine (hr decade-1) of three rice growing seasons in NW Bangladesh 

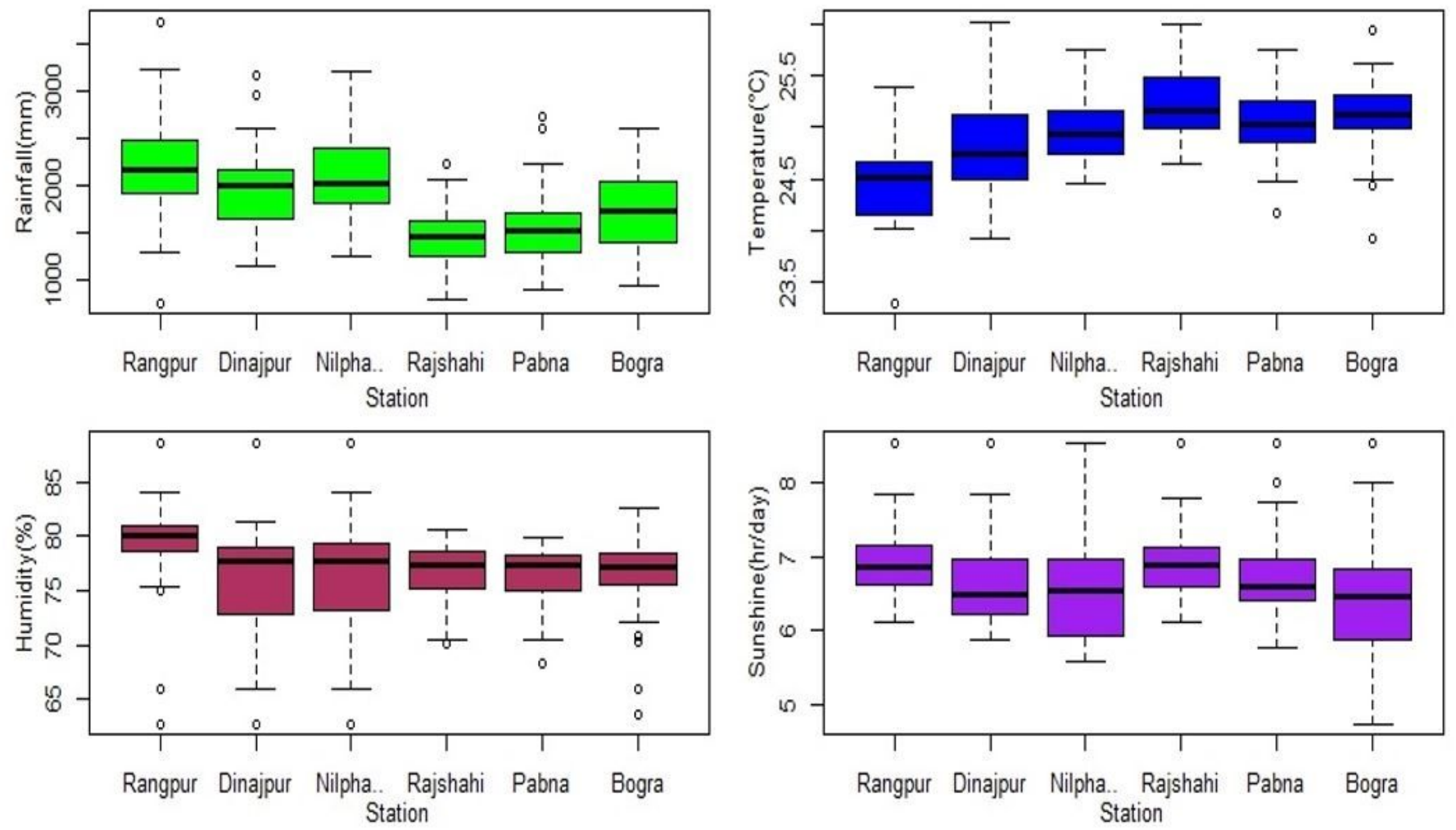

Figure 5

Temporal variation of climatic parameters in northwest Bangladesh during study period

\section{Supplementary Files}

This is a list of supplementary files associated with this preprint. Click to download.

- Supplementarymaterialfinal06092021.docx 